\title{
ICELW \\ The International Conference on E-Learning in the Workplace
}

June 13th-15th, 2012 • Columbia University • New York, NY, USA

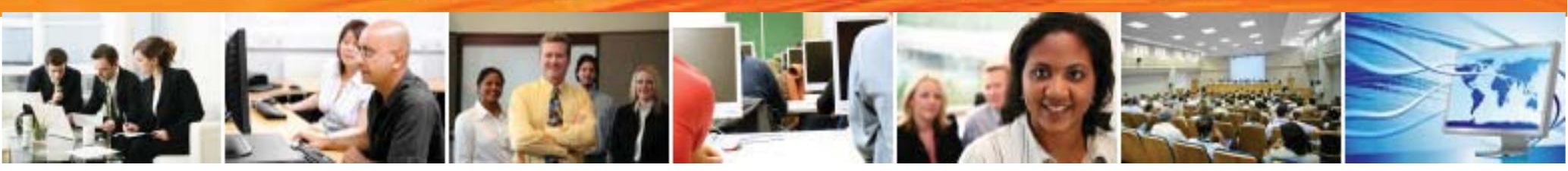

ICELW is an international conference focused on e-learning in the workplace.

With researchers and practitioners coming from around the globe-and from both university and business settings-the ICELW community works to improve online learning so that

CALL FOR PRESENTATIONS, PAPERS, AND IDEAS DEADLINE:

DECEMBER 15, 2011 it makes a measurable difference in workplace performance and morale.

By uniting the corporate and academic worlds, ICELW is creating a new synergy-one with the unique capability to realize the vast potential of e-learning in business, industry, and government.

\section{Who Should Present or Participate?}

ICELW welcomes anyone with a background or interest in e-learning in the workplace-researchers, consultants, and corporate trainers, managers, and directors.

\section{Conference Topics}

The ICELW program will explore a wide range of topics relating to e-learning in the workplace:

- Online training methodologies (simulations, case-based learning and the like)

- Just-in-time learning

- Mobile learning

- Collaborative and social learning

- E-learning design and usability studies

- Performance support systems

- E-learning experiences in large and small organizations

- Authoring tools and Learning Content Management Systems (LCMSs)

- E-learning evaluation

- Other pertinent topics from the ICELW community

The conference will use a variety of engaging formats to convey knowledge and show application, such as presentations, panel discussions, demonstrations, and brainstorming sessions.

\section{Submissions}

If you're interested in presenting at ICELW, please submit a proposal describing your session: what you'd like to present or discuss, and what session format you envision. Please use the ICELW submission form found at www.icelw.org and send your form to proposals@icelw.org. Proposals are due on December 15, 2011. 